\title{
A "FEIRA DE RUA DE LIVROS DE FLORIANÓPOLIS" COMO AMBIENTE ESTIMULADOR DA LEITURA NA ESCOLA
}

\author{
LA "FERIA DE LA CALLE DE LIBROS DE FLORIANÓPOLIS" COMO \\ AMBIENTE ESTIMULADOR DE LA LECTURA EN LA ESCUELA
}

\author{
Francisco das Chagas de Souza - chagas@cin.ufsc.br \\ Doutor em Educação pela UNIMEP. \\ Professor Associado II do Departamento de Ciência da Informação/UFSC. \\ Maria Prazeres Euzébio - praeuzebio@hotmail.com \\ Bacharel em Biblioteconomia pela UFSC.
}

\begin{abstract}
Resumo
Apresenta resultado de pesquisa cujo objetivo proposto foi analisar discursos de docentes e de pessoal atuante em bibliotecas de escolas da rede de ensino de Florianópolis acerca da estimulação que as atividades de incentivo à leitura oferecidas aos alunos de duas escolas na Feira de Rua de livros de Florianópolis, nos anos de 2007 e 2008, exerceram sobre esses. Na coleta de dados verbais aplicou-se entrevista com oito perguntas abertas. Os participantes do estudo foram quatro professores, dois de Geografia, um de Português (os três de $5^{\underline{a}}$ à $8^{\underline{a}}$ séries), uma professora da $2^{a}$ série e dois profissionais responsáveis pelo atendimento nas bibliotecas das escolas. A pesquisa de caráter exploratório empregou a técnica do Discurso do Sujeito Coletivo (DSC) para o tratamento e análise dos dados coletados. Pelos resultados obtidos, pode-se dizer que as atividades de leitura disponibilizadas na Feira de Rua de Livros contribuíram para um maior envolvimento dos alunos nas atividades de leitura na escola.
\end{abstract}

\section{Palavras-Chave}

Feira de rua do livro. Incentivo à leitura. Biblioteca escolar.

\section{INTRODUÇÃO}

O acesso ao livro ainda representa um dos principais problemas a afetar a educação e o desenvolvimento social, econômico e cultural no Brasil. Isso decorre de vários fatores; mas se pode ressaltar como principais o custo do livro, o seu permanentemente precário sistema de distribuição e a oferta a preços incompatíveis com a renda da maior parte da população.

No tocante à sua distribuição, o livro ofertado no mercado brasileiro transita por dois meios principais: vendas das editoras para as livrarias e vendas diretas ao governo. Contudo, há uma terceira forma de oferta muito significativa que se dá pela venda direta na escola, com o mesmo 
desconto aplicado para os livreiros (de 40 a 50\% do preço de capa) (EARP; KORNIS, 2005). Esse caminho aparece como uma solução para atenuar um dos principais problemas das editoras na distribuição de sua produção, que está associado à extensão continental do país. Para essas empresas, ficaria pouco lucrativo enviar pequenas quantias de livros para lugares distantes, pois as distribuidoras trabalham com uma margem de lucro de 10 a 15\% do preço de capa.

Um dos gargalos para o acesso ao livro no Brasil é que $90 \%$ dos municípios não possuem livrarias e mesmo nas regiões mais desenvolvidas é escassa a presença desses estabelecimentos. Quando instaladas nas áreas mais centrais das cidades as livrarias possuem custos fixos elevados, pois precisam comprar os livros das editoras, uma vez que não conseguem formar estoque por consignação (EARP; KORNIS, 2005).

De acordo com grande parte dos livreiros, outro problema que Ihes atrapalha é a concorrência desleal, tanto dos pontos de venda não convencionais, como pelas vendas realizadas diretamente pelas editoras nas feiras de livros, ou a venda de livros didáticos diretamente às escolas. É que nesses casos, são oferecidos descontos mais generosos que os ofertados aos livreiros.

Por outro lado, as bibliotecas no Brasil são poucas. De acordo com o Instituto Brasileiro de Geografia e Estatística (IBGE, 2005), com a Pesquisa de Informações Básicas Municipais (MUNIC), as bibliotecas públicas estão entre os equipamentos sociais mais presentes nos municípios brasileiros. São 6.545 bibliotecas localizadas em 4.726 municípios (85\% do total), com uma relação de 1,2 bibliotecas por município. Porém são pobres, isoladas e mal administradas.

Algumas bibliotecas possuem estoques de livros que poderiam ser utilizados em outra biblioteca ou mantém acervos de títulos antigos, consagrando a idéia de que nelas não adiantaria procurar-se por um título novo, pois não há.

No plano das pretensas soluções, entra em cena uma das mais fortes ações do governo, consistindo na compra livros didáticos através do Programa Nacional do Livro Didático (PNLD). A finalidade desse Programa é a aquisição do livro para distribuição às escolas das redes públicas. Uma justificativa para esse Programa é que esses livros são vendidos ao governo por preço unitário muito inferior ao das vendas feitas aos demais clientes. Mas esse aparente benefício às empresas do ramo editorial não satisfaz a todo o setor. Há empresários que criticam a sistemática empregada, sob a alegação de que ela não atende a todos os custos editoriais. Com isso, há o repasse de parte desses custos aos demais livros vendidos no mercado, em particular, aos exemplares de um mesmo título destinado aos estudantes da escola privada. Essa parcela de público das editoras tende a sofrer um significativo ônus, tendo em vista que as vendas ao governo respondem por mais de $80 \%$ dos valores envolvidos (OLIVEIRA, 2008). 
Embora as feiras de livros constituam um canal cada vez mais presente na distribuição, ela representa um baixo volume percentual no montante de exemplares vendidos; a grande motivação dos editores em mantê-las é que servem como espaço promocional e estão abertas ao acesso de todo tipo de público, principalmente das pessoas que gostam de ler, mas, que têm pouco poder aquisitivo. Nesse espaço, esse público geralmente pode comprar livros bons a preços acessíveis.

A história das feiras acompanha a história do livro impresso. Elas surgiram no século XV, quando os primeiros impressores perceberam que tinham um problema: como vender seus livros. Esse era um típico problema da vida cotidiana daqueles produtores e que necessitava da institucionalização de novas soluções ou nova rotina. O caminho buscado por esses impressores consistiu no envio de representantes às cidades, grandes ou pequenas, com a finalidade de localizar todos os compradores potenciais dos livros à venda. Alguns volumes eram levados a uma cidade por ocasião de uma festa local, onde ocorria uma concentração maior de pessoas e mercadores vindos de regiões distantes. Essas pessoas satisfeitas com os lucros obtidos em seus negócios compravam algum livro ou almanaque.

Com essa origem começa a prática da venda de livros nas feiras, que se estendeu na França, e ainda mais na Inglaterra. Desse modo, as grandes feiras se tornaram locais de encontro de livreiros e impressores. Nesses encontros eles faziam as contas, liquidavam dívidas, compravam o material tipográfico necessário, anunciavam a publicação de um livro, razões mais que significativas para levar os livreiros e impressores a frequentar as grandes feiras. Inicialmente, a feira mais importante foi a de Lyon, na França. Lyon recebia todas as mercadorias que a Europa comercializava particularmente as sedas $\mathrm{e}$ as especiarias. Ao longo do século XVI, desenvolveram-se outras feiras de livros que adquiriram importância ainda maior, destacando-se as feiras de Frankfurt (HIPERLIBRO, [200-?]).

No Brasil, as feiras de livros tiveram início no ano de 1951. A primeira Feira Popular do Livro, organizada pela Câmara Brasileira do Livro (CBL), na Praça da República em São Paulo, foi criada com intuito de inserir no país a tradição européia das feiras de livros encontradas na França, Alemanha e Itália. Em 1961, a CBL em parceria com o Museu de Arte de São Paulo (MASP), realizou a 1a. Bienal Internacional do Livro e das Artes Gráficas. A cada edição essa feira registra o crescimento contínuo de público. $\mathrm{Na} 20^{\text {a }}$ Bienal, em 2008, foi verificada a presença de cerca de 30 mil estudantes do Ensino Fundamental que a visitaram acompanhados de seus professores e nela participaram de atividades de incentivo à leitura e do lançamento do programa Minha Biblioteca, realizado em a parceria com a Secretaria Municipal de Educação.

Essas feiras de livros se estenderam por todo o Brasil, como a realizada em Porto Alegre, desde 1955, organizada pela Câmara Rio-Grandense do Livro (CRL). Sua primeira edição ocorreu 
pela motivação de um grupo de expositores que resolveu instalar 14 estandes para comercializar livros em plena Praça da Alfândega. A feira do livro de Brasília teve início em 1982, organizada pela Câmara do Livro do Distrito Federal (CLDF) e desde o seu início deu sinais de que se tornaria uma referência entre livreiros, bibliotecários, editores e os leitores de diferentes partes do Brasil. Nessa feira destacam-se programas como o projeto Ler é Legal, realizado em parceria com a Secretaria de Educação, a Câmara do Livro. Ler é Legal destina-se à compra de livros pelas escolas da rede pública. Por ocasião da Feira, uma comissão de alunos, representando cada escola pública, irá ao local onde ela está instalada para escolher e comprar livros, usando bônus fornecidos para as salas de leitura da escola.

No Estado de Santa Catarina, há feiras de livros realizadas por iniciativa da Câmara Catarinense do Livro $(\mathrm{CCL})^{1}$ em algumas cidades do estado como: Lages, Joaçaba, Brusque, Timbó, Criciúma, Tubarão, Palhoça, Biguaçu, São José. Em Florianópolis, desde 1986 são realizadas feiras de livros e, atualmente, há dois eventos, a Feira do Livro e a Feira de Rua de Livros. A Feira de Rua é montada na Praça da Alfândega, no centro histórico da cidade, com acesso gratuito às suas instalações. A feira, durante a sua realização no período estudado recebeu a cada dia a visita de aproximadamente 20 escolas das redes pública e particular instaladas na região da grande Florianópolis. Nela é realizado um programa de incentivo à leitura, como espaço para estimular o imaginário das crianças. A título de ilustração, a última edição da feira, realizada após o encerramento desta pesquisa, ocorreu dos dias 06 a 18 de dezembro de 2009. Nela passaram aproximadamente 280 mil pessoas e foram vendidos em torno de 90 mil títulos ${ }^{2}$.

O contexto dessa Feira de Rua de Livros de Florianópolis foi tomado como tema para o desenvolvimento da pesquisa que constitui a base deste artigo. O objetivo geral pretendido foi analisar se as atividades dirigidas ao incentivo à leitura oferecidas na Feira durante as visitas feitas por alunos e professores de duas escolas da rede de ensino de Florianópolis estimularam o aumento da leitura de alunos na sala de aula e na biblioteca de cada escola. Considerou-se em relação ao fator tempo focalizar-se as visitas realizadas nos anos de 2007 e 2008. Foram

\footnotetext{
${ }^{1}$ De acordo com o seu site (http://www.cclivro.org.br/html/quemsomos.php, com acesso em 10 mar. 2010), "A Câmara Catarinense do Livro é uma entidade sociocultural [...] criada com o objetivo de unir as entidades literárias e os livreiros de Santa Catarina, bem como promover e divulgar a obra dos autores catarinenses." É sucessora da ACEL - Associação Catarinense de Livreiros e Editores, que fora criada em 1970, tendo como principal objetivo "a realização de uma grandiosa feira em praça pública que estimulasse o hábito da leitura entre as diferentes classes sociais". Porém foi somente em 1986, que a ACEL realizou a primeira edição da Feira do Livro de Florianópolis, com o objetivo de aproximar o livro e o escritor do público. Complementando, no anúncio da 22a . Feira do Livro de Florianópolis há a seguinte afirmação (http://www.amigosdolivro.com.br/lermais_materias.php?cd_materias=5063, com acesso em 10 mar. 2010): "deixamos o espaço aberto para que escritores, escolas, artistas e grupos catarinenses diversos participem e exponham seus trabalhos e sua arte, em uma parceria para que a cultura catarinense seja apreciada e valorizada". Desse modo, "teatro, música, dança, teatro de bonecos, contação de histórias, declamação de poesia, manifestações culturais, exposições e o tudo que sua criatividade conseguir produzir tem espaço garantido na Feira de Rua do Livro de Florianópolis".
} 
definidos como objetivos específicos: levantar as atividades desenvolvidas na feira visando ao incentivo à leitura; identificar os meios adotados pelos professores visando a incentivar os alunos ao uso da biblioteca; verificar a freqüência de utilização da biblioteca por alunos e professores durante o semestre letivo no desenvolvimento de atividades de incentivo à leitura; identificar o perfil e as práticas de leituras dos estudantes/usuários que compareceram à feira.

\section{AMBIENTE DE REALIZAÇÃO DA PESQUISA}

Nesta seção faz-se uma breve caracterização das duas escolas onde se fez a coleta de dados via entrevistas, identificando-as como A e B. Essa caracterização tem como propósito expor o contexto específico em que são realizadas as atividades de mobilização à leitura, do que a vista à Feira de Livros constitui parte.

A "Escola A" está localizada ao norte da ilha de Santa Catarina. Foi fundada em 15 de novembro de 1959. Funcionou, inicialmente, com a oferta de ensino de $1^{\underline{a}}$ a $4^{\underline{a}}$ séries, em outro endereço. Em 31 de julho de 1988 inaugurou-se o prédio em que está atualmente sediada, que foi construído no terreno de uma família tradicional do bairro onde se encontra. O nome da escola representa uma homenagem ao patriarca da família. No ano de 2009 a escola comemorará o seu cinqüentenário, com homenagens e festividades junto à comunidade. A escola atende o ensino fundamental, contando com 598 (quinhentos e noventa e oito) alunos.

O quadro de pessoal do estabelecimento é composto de: 8 (oito) docentes que atendem de $1^{\mathrm{a}}$ a $4^{\mathrm{a}}$ séries; 18 (dezoito) docentes que atendem de $5^{\mathrm{a}}$ a $8^{\mathrm{a}}$ séries; 3 (três) auxiliares de ensino; 3 (três) especialistas, sendo: 2 (duas) supervisoras escolares e 1 (uma) administradora escolar; 1 (um) bibliotecário; 1 (um) diretor; 1 (um) assistente administrativo; 1 (um) secretário; 2 (duas) merendeiras e 4 (quatro) serventes.

A escola oferece os projetos de: Oficina de Alfabetização de Apoio Pedagógico - realizado por 2 (duas) professoras readaptadas; Hora do Conto - realizado por 1 (uma) professora de Português readaptada; Karatê - realizado em parceria com a Fundação Catarinense de Esporte (FESPORTE).

A "escola B" está localizada no centro de Florianópolis. Foi fundada em 25 de maio de 1912. Sua sede está em edifício construído em estilo arquitetônico neoclássico, com tijolos maciços e assentados em óleo de baleia, conservando ainda hoje todas as suas características originais, das quais se pode destacar o pátio interno, circundado por um corredor alpendrado, onde se salientam as colunatas de ferro. $O$ seu acervo administrativo contém registros e notas

\footnotetext{
${ }^{2}$ FONTE: http://www.cclivro.org.br/html/eventos.php?id_evento=2. Acesso em: 10 mar. 2010.
} 
desde 1912. Nos anos da década iniciada em 1991, o edifício da Escola foi tombado pelo Patrimônio Cultural e seu mobiliário produzido nos Estados Unidos e no estado de São Paulo foi enriquecer o acervo do museu da Universidade Estadual de Santa Catarina (UDESC), em Florianópolis. Inicialmente, funcionava como Grupo Escolar e atendia no ensino de $1^{\underline{a}}$ a $4^{\underline{a}}$ séries. Cinqüenta e nove anos depois a escola inclui as séries de $5^{\underline{a}}$ a $8^{\underline{a}}$, passando a denominar-se Escola Básica. Em 1973, ao ser unida a um Grupo Escolar foi denominada Escola Básica de Demonstração. Durante seis anos, as duas unidades escolares dividiram seus espaços. Uma atendendo de $1^{\underline{a}}$ a $4^{\underline{a}}$ séries e a outra de $5^{\underline{a}}$ a $8^{\underline{a}}$ séries. Em 1993 foi autorizado o Ensino Médio e a Escola foi transformada em Colégio Estadual. Em abril de 2000, passou a designar-se Escola de Educação Básica.

Desde 2002, a Comunidade Escolar, apoiada na decisão comunitária, realiza eleições para diretores. A última eleição ocorreu em 2006 e contou com a participação de todos os segmentos da Comunidade Escolar. O Projeto Político Pedagógico (PPP) ampara-se legalmente na Lei de Diretrizes e Bases da Educação Nacional (LDB), na Lei Complementar oㅡ 170 do Sistema Estadual de Educação e na proposta Curricular do Estado de Santa Catarina.

Como suporte técnico, sua equipe busca a filosofia da práxis, que explica o mundo natural, a história, a sociedade, o homem, a mulher e a cultura como totalidade em sua concreticidade.

O quadro de pessoal da Escola é composto de: 14 (catorze) administrativos, 39 (trinta e nove) docentes sendo 9 (nove) Admitidos em Caráter Temporário (ACT), 8 (oito) funcionários da Associação Pais e Professores (APP), 2 (duas) merendeiras, 4 (quatro) serventes e 2 (dois) vigilantes.

Atualmente, a escola atende a um total de 642 (seiscentos e quarenta e dois) alunos, sendo 204 (duzentos e quatro) de $1^{\underline{a}}$ a $4^{\underline{a}}$ séries, 295 (duzentos e noventa e cinco) de $5^{\underline{a}}$ a $8^{\underline{a}}$ séries e 143 (cento e quarenta e três) de ensino médio. Em 2009 a escola passou a oferecer para os alunos no contra turno Reforço Pedagógico e Oficina de Artes.

Desde 2003, com objetivo de incluir e ampliar as oportunidades de acesso e permanência de surdos no contexto sócio educacional, a Escola conta com a atuação de interpretes de Língua Brasileira de Sinais (LIBRAS) na sala, auxiliando os 14 (catorze) alunos portadores da deficiência de $5^{\underline{a}}$ a $8^{\underline{a}}$ séries.

\section{ASPECTOS TEÓRICOS E METODOLÓGICOS DA PESQUISA}

Nesta seção, apresenta-se a base que deu fundamento teórico e suporte para a escolha da metodologia empregada no estudo. O tema selecionado como referência para a análise foi a Feira do Livro, considerado como ambiente propício à estimulação do interesse e das práticas de 
leitura, sobretudo para o público escolar. Nesse sentido, olha-se para uma realidade que se constitui socialmente como ambiente que se materializa pela interação de pessoas. No espaço social, pessoas assumem papéis diversos, conforme seja a sua participação predominante nas interações existentes. No ambiente de uma feira de livros se explicitam e convivem os papéis de vendedor, promotor cultural, autor, editor, consumidor de livros ou leitor e outros. Tais sujeitos sociais ao cumprirem seus papéis estão situados dentro de um ambiente em que a primeira ação é a de comunicação e para isso dependem da linguagem que, por sua vez, é o instrumento humano básico para a socialização interpessoal.

Esses conceitos são disposições teóricas necessários para se poder estudar e interpretar os fenômenos que são identificados num ambiente de ação humana. Para melhor se perceber esse ambiente foi utilizado neste estudo, como fonte básica a obra Construção Social da Realidade, de Berger e Luckmann (1985), situada no âmbito da chamada Sociologia do Conhecimento. Através dessa obra é possível compreender-se como uma sociedade é construída através da interação das pessoas por seus papéis sociais, linguagem, comunicação, interação e socialização. A compreensão destas noções foi tomada como fundamental para o entendimento da realidade escolhida para ser pesquisada.

Uma noção expressiva, quando se pensa em socialização, é a da interiorização. Com esse conceito pode-se compreender que o homem constrói a realidade social ao mesmo tempo em que é influenciado por ela. Em criança, o primeiro contato humano é a comunicação com os pais, irmãos, com a família. É nesse momento que o individuo se torna membro da sociedade e a primeira coisa que acontece é a formação da identidade a partir do que é capaz de interagir na comunidade. Para Berger e Luckmann (1985, p. 176),

a criança identifica-se com os outros significativos por uma multiplicidade de modos emocionais. Quaisquer que eles sejam, a interiorização só se realiza quando há identificação. A criança absorve os papéis e as atitudes dos outros significativos, isto é, interioriza-os, tornando-os seus.

A essa socialização desenvolvida na infância, os autores chamam de primária, porque o individuo aceita tudo indiferentemente, devido à confiança nas pessoas que compõem aquele ambiente. Em um segundo momento, o indivíduo já primariamente socializado se envolve em outros ambientes em que ele tem que estudar ou trabalhar, ou conviver. Dentro desses outros ambientes, de características institucionais, ocorre a socialização que os autores chamam de secundária. É com essa socialização que o indivíduo expressa o que já adquiriu como conhecimento que pode ser objetivado. Com isso se torna capaz de identificar a função de cada pessoa, ou melhor, pode identificar o papel social de cada indivíduo: professor (a), chefe, sacerdote, policial, bibliotecário e outros. Berger e Luckmann (1985, p. 106) enfatizam que 
[...] tais papéis têm grande importância estratégica numa sociedade, uma vez que representam não somente esta ou aquela instituição, mas a integração de todas as instituições em um mundo dotado de sentido.

A socialização, assim, inicia-se com a interiorização de conhecimentos que vêm do convívio do indivíduo com os outros, do conhecimento das coisas, da compreensão dos outros como semelhantes. Isso implica "em qualquer caso, na forma complexa da interiorização, não somente", que compreendo "os processos subjetivos momentâneos do outro, mas" que compreendo "o mundo em que ele vive e esse mundo torna-se o meu próprio". (BERGER; LUCKMANN, 1985, p. 174).

Em sua existência, a interiorização implica em recepção de conhecimentos externos que são objetivados por outrem e chegam ao indivíduo e que uma vez recebidos serão tratados em sua mente ou subjetivados, com base no conhecimento de que dispõe. As idéias e opiniões que virá a expressar corresponderiam à objetivação que ele produzirá. De outro lado, nem tudo o que está objetivado na sociedade torna-se subjetivo para o individuo ou é por ele interiorizado. Isso quer dizer que o individuo somente interiorizará aquilo que the interessa. Apenas o que ele precisa para tornar subjetivo, porque

Há sempre mais realidade objetiva disponível do que a efetivamente interiorizada em qualquer consciência individual, simplesmente porque o conteúdo da socialização é determinado pela distribuição social do conhecimento (BERGER; LUCKMANN, 1985, p. 179).

Assim, a realidade da vida cotidiana envolve o indivíduo na partilha com o outro e é representada por meio de sinais e pela linguagem. A transmissão do conhecimento se dá pela objetivação, que mediante o contato pessoal, face a face, permite ao indivíduo sentir a expressão, a reação do outro, como por exemplo, em uma biblioteca, onde o bibliotecário, usuários e funcionários interagem ou em uma feira, onde as chances de recepção são várias. No momento de interação ocorre a assimilação que leva à subjetivação.

Nesse sentido, é também de muito valor a compreensão que se obtém da constituição do espaço institucional. As instituições (igreja, escola, feira, bibliotecas, etc.) se originam normalmente em coletividade, porque resultam de compartilhamento. Formam-se quando há uma tipificação recíproca de ações habituais por tipos de atores (indivíduos), quando os indivíduos praticam os mesmos papéis com os quais em certo momento realizam ações juntos ou separadamente. Berger e Luckmann (1985, p. 83), em comentário a essa questão, assinalam que: 
A divisão do trabalho e as inovações conduzirão à formação de novos hábitos, maior expansão do terreno comum a ambos os indivíduos. Em outras palavras, um mundo social estará em processo de construção, contendo nele as raízes de uma ordem institucional em expansão.

Quando as objetivações, que constituem o ambiente da instituição, têm que ser passadas adiante a uma nova geração, não podem ficar retidas a apenas um grupo de pessoas. Por isso, dependem da linguagem como forma de transmissão das significações objetivadas de maneira que quem não participou da experiência original possa entendê-la. Esse processo então requer a legitimação, a justificação, a explicação do que está sendo feito. De acordo com Berger e Luckmann (1985. p. 128-129):

A legitimação justifica a ordem institucional dando dignidade normativa a seus imperativos práticos. [...] A legitimação não apenas diz ao indivíduo por que deve realizar uma ação e não outra; diz-lhe também por que as coisas são o que são. Em outras palavras, o "conhecimento" precede os "valores" na legitimação das instituições.

Essas idéias justificam assim, porque a metodologia empregada requer a busca da objetivação do pensamento dos participantes selecionados, a partir das funções que ocupam nas escolas escolhidas. Além disso, reforçam o sentido de interação que também se estabeleceu entre pesquisadores e informantes.

\section{METODOLOGIA EMPREGADA}

Para o desenvolvimento da pesquisa fez-se uma abordagem mais geral de caráter qualitativo, em que se buscava a compreensão de um fato, o reconhecimento de significado que poderia ser expresso pelos informantes tendo em vista a sua avaliação sobre um objeto de interesse inserido em sua prática cotidiana: a possibilidade da visita a uma feira de livros por estudantes gerar estímulos ao aumento da leitura na sala de aula e na biblioteca da respectiva escola. Esse esforço em reconhecer a percepção que uma população manifesta em relação à sua ação parece mais bem demonstrado com o discurso, pela razão de que há aspectos da realidade que não se expressam adequadamente com o uso de instrumentos quantificadores. Alves (2003, p. 56) afirma como uma característica da pesquisa qualitativa que nela:

o pesquisador procura captar a situação ou fenômeno em toda a sua extensão; trata de levantar possíveis variáveis existentes e, na interação, o verdadeiro significado da questão, daí a experiência do pesquisador ser fundamental; [...] colhe informações, examina cada caso separadamente e tenta construir um quadro teórico geral.

Esse entendimento em torno do envolvimento do pesquisador no reconhecimento dos 
significados existentes em dada situação é exposto por Minayo (2002, p. 21) quando ressalta que a pesquisa qualitativa:

Trabalha com o universo de significados, motivos, aspirações, crenças, valores e atitudes, o que corresponde a um espaço mais profundo das relações, dos processos e dos fenômenos que não podem ser reduzidos à operacionalização de variáveis.

Considerando-se quanto aos objetivos, a pesquisa teve caráter exploratório, e empregou uma etapa de levantamento bibliográfico, com o fim de melhor explorar o ambiente de atuação do profissional responsável pela biblioteca escolar, tendo a formação em Curso de Biblioteconomia ou num dos campos da licenciatura. No que tange ao campo de coleta de dados discursivos, acredita-se que essa modalidade permite o aprofundamento do conhecimento da realidade, pois possibilita a explicação da razão de ser e do por que das coisas, conforme afirma Gil (1993).

O estudo teve a participação de quatro professores atuantes em sala de aula e dois profissionais responsáveis que atendem na biblioteca de duas escolas da rede de ensino de Florianópolis. Dos professores envolvidos dois foram da área de Geografia de $5^{\text {a }}$ à $8^{\underline{a}}$ séries, um de Português de $5^{\underline{a}}$ à $8^{\underline{a}}$ séries, uma professora da $2^{\underline{a}}$ série. Com a sua participação, pretendeu-se investigar se as atividades dirigidas ao incentivo à leitura, oferecidas na feira durante suas visitas em 2007/2008, estimularam o aumento da leitura de alunos na biblioteca da escola. aparentemente limitado número de participantes se justifica pelo fato acima explicado, de que o esforço de pesquisa estava direcionado para a busca de significados que docentes atribuem a um determinado componente da realidade: o estimulo que dado trabalho oferece para a realização da leitura. Também houve outra fonte de informação, a Câmara Catarinense do Livro (CCL), que facultou 0 acesso aos seus arquivos, permitindo que se pudesse conhecer a movimentação das escolas e suas demandas de frequência no evento. A escolha dos docentes e profissionais participantes ocorreu por estarem presentes nos estabelecimentos selecionados, prestando contribuição ativa na promoção da leitura na biblioteca e no contexto escolar; também por estarem em contato direto com o aluno/usuário, reforçando cotidianamente a importância do livro e da leitura. A busca pela CCL, dada a natureza dos dados necessários, foi feita por telefone, seguida da troca de correspondência eletrônica. A despeito da atenção inicialmente recebida, houve alguma demora entre a solicitação inicial das informações (janeiro de 2009) e seu atendimento (início de março de 2009).

A coleta de dados discursivos foi realizada por meio de entrevista em que as respostas foram gravadas em aparelho digital mp3 e posteriormente transcritas. Para a obtenção dessa coleta foi elaborado um roteiro contendo oito questões abertas construídas de modo a estimular respostas discursivas mais extensas, decorrentes de reflexão dos entrevistados na sequência de apresentação das perguntas. Esse instrumento foi aplicado em situação de pré-teste em março de 
2009, com a participação de dois professores, um de português e o outro de geografia, e um profissional responsável da biblioteca da escola da mesma rede de ensino. O emprego da entrevista, além de corresponder melhor à fundamentação teórica adotada, conforme já explicitado, é também uma forma de interação social, aplicada no contexto das ciências sociais. De outro lado, permitiu a produção de material discursivo a ser analisado. Essa conduta exigiu uma significativa atenção ao modo de perguntar, pois isso é importante para o emprego da metodologia, pois como afirmam Lefèvre e Lefèvre (2005, p. 15):

[...] é preciso perguntar de modo a ensejar que as pessoas expressem um pensamento, ou seja, um discurso, o que só pode ser feito através de questões abertas.

A realização da coleta definitiva das entrevistas ocorreu em abril 2009, após contatos telefônicos para agendamento. A fim de atender a aspectos éticos, foi apresentado aos participantes e por eles assinado um Termo de Consentimento Livre e Esclarecido (TCLE). Esse instrumento permite a obtenção prévia da aceitação do participante em conceder a entrevista, representando um acordo assinado entre pesquisadores e pesquisados. Com isso ficou claramente estipulado o compromisso com o anonimato pelo qual os respondentes não teriam suas respostas identificadas de modo individualizado.

As entrevistas tiveram início na "Escola A“ com a professora de geografia, identificada como ED1. Antes da entrevista, a professora foi à sala de aula aplicar um trabalho para os alunos, ficando como responsável da tarefa a auxiliar de sala. A entrevista teve duração de 15 minutos e foi realizada sem a presença de outras pessoas.

A segunda entrevista foi realizada no dia seguinte, também na "Escola A" com a bibliotecária, na própria biblioteca e de portas fechadas, com tempo aproximado de 15 minutos. Essa entrevista foi identificada como ERB1. A terceira entrevista também se deu no segundo dia, na mesma "Escola A" e foi realizada com a professora de português na sala dos professores. Durante a entrevista pode-se perceber que havia barulho provindo do pátio da Escola, porque alguns alunos não tinham aula no momento. O tempo aproximado da entrevista foi de 15 minutos. Esta entrevista foi identificada como ED2.

A coleta de dados continuou na segunda escola, designada como "Escola B". A primeira entrevista realizada envolveu a professora de geografia, que ministrou prova para a sua turma que a respondia enquanto a entrevista realizava-se no corredor. Sentada em um banco em frente à sala de aula, que foi deixada com a porta aberta para que pudesse ser feito o acompanhamento do movimento dos alunos, a professora respondeu às questões entre o barulho da sala somado ao dos alunos que chegavam atrasados. A duração da entrevista foi de aproximadamente 10 minutos. Essa entrevista foi identificada como ED3. 
A segunda entrevista nessa Escola foi realizada no mesmo dia com a participação da professora da segunda série e ocorreu na sala de aula com a presença dos alunos. Ao longo da entrevista as crianças comportaram-se bem e a entrevista foi aplicada em aproximadamente 15 minutos. Essa entrevista foi identificada como ED4. Em seguida, foi entrevistada a responsável pela biblioteca, uma professora de $1^{\underline{a}}$ a $4^{\underline{a}}$ séries, readaptada, que atende naquele setor. A entrevista foi realizada na biblioteca, de portas fechadas, e teve a duração aproximada de 10 minutos. Esta entrevista foi identificada como ERB2.

Após sua coleta, os dados foram tratados com a utilização da Técnica do Discurso do Sujeito Coletivo (DSC). Essa Técnica, segundo seus autores (LEFÈVRE; LEFÈVRE, 2005, p. 19), representa

[...] uma estratégia metodológica que, utilizando uma estratégia discursiva, visa tornar mais clara uma dada representação social, bem como o conjunto das representações que conforma um dado imaginário.

Com uso desta técnica, ressaltam Lefèvre e Lefèvre (2005, p. 32), permite-se "deixar a realidade descrever-se automaticamente". Para confeccionar o DSC existem as seguintes figuras metodológicas: Expressões-chave (ECHs), Idéias Centrais (ICs) e Ancoragem (AC), abaixo descritas, e o DSC, que constitui a síntese final do conteúdo central dos discursos proferidos. Para a pesquisa que deu origem a este artigo utilizou-se somente as ECHs, as ICs e elaboraram-se dois DSCs: um tendo origem nos discursos dos professores e o outro originado nos discursos dos responsáveis pelas bibliotecas.

Para melhor esclarecer as figuras metodológicas da Técnica do DSC, apresenta-se a síntese a seguir:

- Expressões-chaves (ECHs) são pedaços ou trechos literais dos discursos que revelam a essência dos depoimentos;

- Idéias Centrais (IC) compreendem a descrição sintética, similar a um termo de indexação, que revela o que foi dito, ou o tema que o sujeito está falando;

- Ancoragem (AC) é uma manifestação lingüística que explicita uma dada teoria, ideologia ou crença. Permite uma análise mais fina do discurso.

- DSC - é um discurso-síntese redigido na primeira pessoa do singular e composto pelas ECH que tem a mesma IC e AC. Na elaboração do DSC é preciso considerar alguns princípios como: coerência e posicionamento próprio.

$\mathrm{Na}$ aplicação das etapas da Técnica de análise visando à construção do DSC, após a 
realização da transcrição dos discursos gravados, digitando-os em processador de texto resposta após resposta, procedeu-se utilizando como estratégia operacional os seguintes passos: 1 Preparação da planilha de análise, chamada de Instrumento de Análise do Discurso (IAD). Essa planilha continha quatro colunas: a primeira apenas para se colocar o código associado a cada entrevistado a fim de se evitar eventual "mistura" das respostas; a segunda para se transferir os discursos já transcritos e digitados; a terceira para se anotar as Expressões-chave (ECHs) e a quarta para se anotar as Idéias centrais (ICs); 2 - Transferência do material já digitado, colocando abaixo de cada pergunta, num mesmo bloco, o conjunto das respostas obtidas. Fez-se isso separadamente para professores e para responsáveis pelas bibliotecas; 3 - Marcação das respostas colocadas na segunda coluna a fim de destacar as ECHs nelas contidas. Fez-se isso com a leitura de cada resposta com o propósito de se extrair dela as Expressões chaves (ECHs) cujo teor trouxesse a explicitação de potencial resposta para os objetivos da pesquisa. Concomitantemente, fez-se o devido registro destas ECHs na terceira coluna do IAD; 4 - Em seguida, foi realizada a leitura das ECHs para nelas identificar e depois anotar na coluna quatro do IAD os termos identificados como ICs. Concluídas estas etapas foi feito o agrupamento das ECHs, a partir das ICs que apresentassem semelhanças temáticas a fim de se organizar 0 Discurso Coletivo de cada questão evidenciado no material analisado; 5 - Fez-se a produção de DSCs de cada questão como forma de melhor percepção de sua articulação interna e das representações mais destacáveis, caso fosse realizada a análise de Ancoragem (AC); 6 - Como etapa final foram reunidos os DSCs parciais por grupo de entrevistados em um DSC geral. Os dois DSCs gerados dessa atividade de análise é o que constitui a seção seguinte.

\section{O DISCURSO DO SUJEITO COLETIVO SOBRE A PRÁTICA DE LEITURA NA SALA DE AULA E NA BIBLIOTECA ESCOLAR}

Nesta seção são apresentados os dois DSCs obtidos: um originado nas respostas dos docentes e o outro provindo das respostas dos responsáveis pelas bibliotecas. Em sua construção, foram considerados os aspectos metodológicos da Técnica do DSC. Esses DSCs abaixo apresentados e o texto que os seguem oferecem ao leitor o conhecimento que foi obtido, analisado e interpretado no desenrolar da pesquisa.

\section{DSC 1 - a visão dos docentes}

A leitura é trabalhada com livro didático; construímos textos coletivos a partir do conhecimento dos alunos, de suas vivências e daquilo que parte do interesse deles. Mas também com textos de fora, que têm a ver com o conteúdo; é a leitura por prazer mesmo, porque o objetivo dessa atividade é o texto; é a leitura para incentivar mesmo, a leitura pelo gosto. Eu digo pra eles não só lerem o livro que está na biblioteca, em tudo o que lerem estão adquirindo alguma coisa nem que seja para saber como se forma uma frase, uma palavra nova que aparece; tem que ser curioso senão não adianta, eu tento sempre estimular nesse sentido. Em geografia têm outros tipos de leitura, por exemplo, mapa, tabela, a leitura de uma legenda, tudo é forma que eu tento explorar. Muitas 
vezes eu pego um texto de português e, ali, entro com a matemática; dali a gente já formou e trabalha com as palavras, palavrinhas chaves, depois eu formo e faço acróstico, ou a gente pega também através de figuras, já contendo as palavras que eles estão conseguindo ler através de gibi. Assim como, as atividades em grupo, por exemplo, eu pedi que eles entrevistassem algum familiar, eles tiveram que colocar no papel o que a outra pessoa falou; leram isso pra sala inteira, foi feito uma tabela comparativa no quadro; a gente está trabalhando a transformação de estoque, por exemplo, em todas as séries, então nessa entrevista eles tiveram todo esse processo, de entrevistar, colocar no papel, a ler, reunir-se em grupo para tentar descobrir o que um tem pra dizer pro outro; estão produzindo um texto sobre isso, vão apresentar esse texto para turma de novo. [Em relação à ajuda de outros profissionais da escola] raramente solicito e, quando solicito, sou atendida não posso reclamar Mas com relação à interdisciplinaridade não consegui ainda conversar com ninguém pra fazer um trabalho em grupo, com grupo de professores. Quando a gente solicita nos encontros pedagógicos eles trazem algo novo; na biblioteca pública quando tem contação de história e atividades com a faixa etária deles a gente vai. Quem sempre dá um apoio é a própria bibliotecária ou a moça que é auxiliar de biblioteca, ela sabe qual o conteúdo que a gente trabalha. Costumo trocar muito com o pessoal de português, tem uma professora que trabalha com a Hora do Conto, da 1a a 4a séries. A bibliotecária está proporcionando um espaço agradável para os alunos estarem mais à vontade; vem contar alguma novidade que chegou; vem até a sala, por exemplo, contar história de maneira lúdica. Hoje é aula de leitura, vai ser no pátio! Então a gente vai pro pátio, escolhe o local e faz a leitura ali; outro dia a gente vai pra biblioteca $e$ cada um vai escolher o seu livro. Na escola, teve o curso de leitura e contação de história; já participei, é bem interessante e faz parte do projeto pedagógico, mas uma das coisas que a escola está priorizando é uso da biblioteca; saíram pra fora quando o Ziraldo esteve aí, eles incentivam bastante, está contemplado no Projeto Político de Escola. No meu plano anual de ensino o objetivo é incentivar a leitura, a escrita, para que esse aluno saiba ler o que ele está vendo, a interpretação dele, não somente decifrar códigos; isso faz parte da nossa meta enquanto escola, a leitura, a alfabetização do aluno é obrigação de todos, não é só do professor de português; incentivar a leitura não é só obrigação do bibliotecário. Procuro trabalhar sempre ligando uma coisa à outra. Esse texto aqui não tem como trabalhar tanto a questão gramatical, mas ele serve pra gente refletir sobre alguma questão. Tudo que se lê, cai informalmente numa prova, cai num trabalho porque acho que a leitura tem esse papel também, o papel de proporcionar o prazer para os alunos; tento sempre de acordo com a proposta de lei, fazer uma leitura pra conteúdo; mas também só por prazer, a leitura só pra interpretação, depois pra comentários, acho que é importante também. Às vezes faço experiência com eles, por exemplo, a questão da água em evaporação. Pego álcool pra ferver e o recipiente, é claro eu não posso tapar pra mostrar que a água do estado líquido, passa para o gasoso. Procuro completar com jogos, algumas coisas depois da sala a gente transforma em concreto, algum trabalho que dentro da idade deles conseguem fazer, criar. [Como, por exemplo,] brincadeiras, algumas dinâmicas, lê agora, escreve, agora produz um texto com relação aquilo, dou um tempo pra fazerem. Tento fazer produção com eles, não só a produção escrita, produção em forma de desenho, eu fiz com as $5 a$ e $6 a$ séries. Penso que serve pra concretizar aquilo que eles leram, aquilo que eles produziram também, através do desenho; acho também que dá pra fazer uma leitura daquilo que a pessoa está querendo expressar, acho que não é uma leitura em forma de palavras. Além [de uso de materiais como] recorte de revista ou jornal, filmes e recurso específico de geografia, mapas grandes para levar pra sala, o globo. Além do mais a escola vai à feira de livros, participa de concursos da Câmara Catarinense de Livros e alguns textos da escola são publicados no livro da Câmara Catarinense. Então sempre tem o incentivo de que na biblioteca tem o livro com o nome dos próprios alunos da escola, e eles continuam vendo que essa maneira do escritor vir à escola como incentivo para eles escreverem e publicarem outros livros. Porque a gente acredita mesmo que o aluno ainda não tem esse hábito da leitura, mas tem que dar a ele a oportunidade para ele ter contato nesse mundo, é um pontapé inicial. Estamos fazendo eles entrarem nesse mundo, se ele realmente vão ter gosto por isso, ou não... Mas é um incentivo, é importante aquele momento, conhecer autores novos, ter a oportunidade de folhear livros, é um outro ambiente. Aqui na escola sempre se vai com esse objetivo de incentivar, porque a gente acredita que pra formar uma pessoa que tem uma capacidade mínima pra chegar a algum lugar, ela tem que ler. Agora, o que eu sei e sinto diferença assim com relação aos próprios alunos: têm alunos que gostam muito 
de ler que adoram ler e têm alunos que já não gostam tanto. Então assim eu vou tentar trazer todo mundo, fazer com que todo mundo leia pelo menos, pratique ali na sala, mas eu também não obrigo porque eu acho que isso não tem que ser uma coisa penosa. É feito trabalho em cima do que eles vivenciaram lá [na feira]. Em forma de cartazes, relatório, de estatística, quais livros chamaram mais atenção, quais livros eles compraram. Todo ano a gente discute, geralmente assim, os problemas que têm. Sempre são referentes à leitura, à escrita. Então o que vai ser a nossa ação esse ano pra tentar resolver. Claro a gente não vai resolver $100 \%$, mas vai tentar resolver esse problema. Cada ano é uma idéia, a gente vai tentando, vai mudando, não deu certo muda de novo, mas eu acho que pelo menos a maioria dos profissionais tenta trabalhar essa forma de enxergar a leitura, a escrita em todas as matérias. Eu vou corrigir um texto de um aluno, então o aluno escreveu errado, isso é pra professora de português? Se eu estou vendo o conteúdo, não tem como desassociar uma coisa da outra, um complementa o outro, se ele escreve bem pra um em português, ele vai escrever pra mim também em geografia.

\section{DSC 2 - a visão dos responsáveis pelas bibliotecas}

Na biblioteca não existe uma estratégia especifica para atendimento de leitura dos alunos, essa leitura ela é elaborada em sala de aula e os professores é que vêm trabalhar com os alunos aqui na biblioteca. São planejados com os professores de português ou outras áreas que estejam sendo trabalhadas naquele momento. Seriam antes das feiras e das atividades de concurso, porque a escola participa de olimpíadas, que são: de astronomia, de matemática, de português. Outras atividades são contempladas no planejamento da escola e as feiras são incluídas nessas atividades. Os professores vêm em busca de materiais que serão usados nas atividades junto aos alunos, que são desde mapas, globos, atlas, dicionários, as gramáticas, os livros de literatura de forma geral, tipos como poesias. A gente presta uma certa assistência. Nós fazemos uso de divulgação de materiais que chegam à biblioteca e vamos às salas de aula conversar com os

alunos. Fazemos com o professor algumas atividades, como: desenvolver interpretação de textos a partir da Hora do Conto, porque temos uma professora especifica que faz a hora do conto. Então é feito com materiais aqui da biblioteca, em sala de aula, e a partir disso são feitas atividades com alunos de cada turma; além dos horários específicos de atendimento na biblioteca, também tem a sala informatizada que faz trabalho em conjunto com a biblioteca. Eu como profissional da escola participo do projeto pedagógico, mas diretamente como responsável da biblioteca, isso não acontece. Todos os anos são feitas reuniões para definir o tema que vai ser trabalhado durante o ano na escola. A biblioteca sempre está junto com os professores no que a gente pode dispor de materiais ou na troca de informações que eles conhecem de outras instituições; que tenham materiais de apoio ou mesmo pessoas que possam estar servindo de suporte informacional como palestras e outras coisas assim. [A leitura] está contemplada nas atividades realizadas em sala de aula, não como atividade da biblioteca, mas especificamente nas próprias disciplinas e nas atividades dos professores, que fazem o planejamento e já disponibilizam um horário especifico de visita toda a semana, então todos os alunos têm um horário especifico de visitação na biblioteca. Os professores têm em seus planejamentos varias atividades pra fazer com os alunos, desde interpretação de textos, alfabetização, o livro didático que é controlado pela biblioteca. A biblioteca é encarregada disso pelo recolhimento e distribuição do livro, o controle desse livro, e se faltar o livro tem que está viabilizando outros títulos. A biblioteca sempre teve suas rotinas envolvendo os dois profissionais, quer fosse o estagiário ou professor readaptado que trabalhasse em conjunto. Fizemos várias atividades em conjunto, sempre com os professores no planejamento, também atuei na olimpíada de Astronomia como colaboradora e nas outras atividades da escola. Foi bem importante para os alunos esse momento que tiveram na biblioteca pra fazer atividades que não são também atos de rotina da escola. Como nada é elaborado especificamente pela biblioteca então cabe ao professor na sua função ou dentro da sala de aula. Não contamos com nenhuma verba destinada ao estimulo a leitura. Tudo que vem pra nós é por parte de doação, tanto doação do Ministério da Educação - MEC, da Secretária da Educação ou da comunidade; a biblioteca nem está contemplada na verba da escola que vem do MEC, porque agora foi cortado. No caso [das visitas às feiras] são os próprios 
professores que acompanham os alunos nessas visitas e, o retorno que a gente vê, é que eles voltam motivados para o empréstimo de livros ou outras atividades aqui na biblioteca. No ano passado eles foram visitar quando o caminhão do Ziraldo veio com a peça teatral do Menino Maluquinho e retornaram com alguns materiais, doaram pra biblioteca; foi feito um intercâmbio $e$ eles pegaram alguns livros do Ziraldo e os professores trabalharam em sala. Em outros momentos se visitou a feira de livros com o pessoal do ginásio, o pessoal mais velho que também participou de textos que foram contemplados, premiados, ganharam livros e foi muito importante pra comunidade e o corpo discente.

\section{INTERPRETAÇÃO DOS DISCURSOS DO SUJEITO COLETIVO}

Percebe-se que foi significativa a realização da pesquisa envolvendo os dois grupos, professor e bibliotecário, pois eles participam do processo de ensino-aprendizagem e percebem, entre si, que ocorre um estímulo à leitura na biblioteca escolar após visita dos alunos à feira de livros. Constatou-se que a Feira de Rua de Livros de Florianópolis proporciona possíveis caminhos de estímulo ao gosto pela leitura. Nesse local, é desenvolvida uma série de atividades; elas incluem apresentações teatrais, musicais, danças, poesias, projeções de filmes, contação de histórias, oficinas literárias e de artes, confecção de fantoches, concurso de textos, o contato com autores e a aproximação com uma grande quantidade de livros que, provavelmente, não se encontra em outro lugar, na categoria infantil; são livros coloridos, com efeitos e novidades; na literatura infanto-juvenil, há livros de aventura e de poesia entre outros.

Soube-se da realização de ações e práticas desenvolvidas nas escolas para levar o aluno a ter contato com os livros; a visita à feira de rua de livros consta no planejamento de atividades da escola, e isso proporciona à criança e ao jovem a possibilidade de escolha individual e disponibiliza uma variedade de chances de acesso à literatura. Faz com que ele perceba que o livro poderá ser encontrado em vários ambientes.

Percebe-se pelo discurso dos docentes em relação à leitura que são desenvolvidas atividades exploratórias que se convertem em poderoso instrumento para aquisição do domínio de novos procedimentos de trabalho. Isso revela, também, a relação que se pode fazer entre as práticas desses professores e a teoria existente sobre a formação do leitor e o fomento à leitura.

Uma das atividades exploratórias realizadas pelos professores é deixar os alunos à vontade na escolha da leitura, tanto que se possuírem livros interessantes em casa possam trazêlos para serem usados em sala de aula. A propósito, Zen (1997, p. 60), em comentário a esse tipo de questão, considerando experiência vivenciada em outro ambiente, assinala que

[...] o objetivo, a partir de então, foi ler, com os alunos em diferentes linguagens. A fala deixou de ser unitária. A posse da palavra também foi concedida a quem sabe: os alunos. 
É de extrema importância a visão de que o aluno necessariamente não precisa ser passivo, ele responde, ele pergunta, dá sugestões, ele toma o seu posicionamento. $\mathrm{O}$ aluno tem que ser crítico. E o professor está buscando novos caminhos dentro da realidade escolar. Essa atitude de busca é destacada por Freire (1993) quando discorre sobre a natureza formadora da docência que não poderia reduzir-se a puro processo técnico e mecânico de transferir conhecimentos; quando enfatiza a exigência ético-democrática do respeito ao pensamento, aos gostos, aos receios, aos desejos e à curiosidade dos educandos; quando alerta que esse respeito não pode eximir o educador, enquanto autoridade, de exercer o direito de ter o dever de estabelecer limites, de propor tarefas, de cobrar a execução das mesmas; quando acentua que sem esses limites as liberdades correm o risco de perder-se em licenciosidade, da mesma forma como, sem limites, a autoridade se extravia e vira autoritarismo.

Um entendimento dessa ordem implica e reforça que não dá para desconhecer que na relação professor/aluno há todo o peso das relações institucionais que estão presentes. Berger e Luckmann (1985, p. 80) dizem sobre isso que:

As instituições, também, pelo simples fato de existirem, controlam a conduta humana estabelecendo padrões previamente definidos de conduta, que a canalizam em uma direção por oposição às muitas outras direções que seriam teoricamente possíveis.

Percebe-se no discurso resgatado que as escolas têm a preocupação com a prática da leitura, pois a contemplam no Projeto Político Pedagógico (PPP); igualmente, percebe-se que os professores estão engajados com essa prática, tanto que não é apenas na disciplina de português que ela se manifesta; em outras disciplinas eles se preocupam em desenvolver atividades para o estimulo à leitura.

O discurso dos professores sobre a sua prática pedagógica engloba também aspectos que dizem respeito ao modo de fazer a estimulação à leitura, empregando um procedimento básico que é o da liberdade de escolha; não só de leitura como de outras atividades, que incluem jogos, brincadeiras, algumas dinâmicas, filmes, músicas, porque tudo será válido no seu devido tempo e com material adequado. Sobre essa postura, Sandroni e Machado (1986) permitem perceber que incentivar o gosto pela leitura também significa criar condições para ler a própria realidade; que o ato de ler vai além do limite do texto; que pode ser realizado a partir de imagens, objetos, situações reais ou imaginadas. É, por isso, que se deve oferecer às crianças a leitura de imagens e a leitura de objetos, que eles denominam "jogo dos livros mudos" e "jogos das coisas". Ainda sobre isso Manguel (2006, p. 83) reflete que 
[...] o poder do leitor não se esgota em sua capacidade de reunir informações, ordenar e catalogar, mas em seu dom de interpretar, associar e transformar as suas leituras.

Pode-se interpretar que é nas atividades desenvolvidas em grupo, com entrevistas e comparações, onde ocorre a leitura compartilhada. Para Zen (1997) essa prática tem peso relevante. A partir de seu entendimento, pode-se dizer que é na vivência de leitura compartilhada que os sujeitos percebem os detalhes dantes não identificados; que estabelecem relações e que divergem quanto à interpretação. Percebe-se que nesse entrelaçamento de opiniões manifestamse as diferentes pistas de raciocínio que conduzem os leitores à construção dos significados.

Ler acompanhado ou em companhia significa para a criança ou para o adulto, a descoberta de novas formas de comunicação, com uma linguagem simples e concreta, pois a linguagem é uma realidade que se partilha com os outros. Em Berger e Luckmann (1985) pode-se entender que a linguagem fornece ao indivíduo a imediata possibilidade de continua objetivação de sua experiência em desenvolvimento. Em outras palavras, a linguagem é flexivelmente expansiva, de um modo que permite ao indivíduo objetivar um grande número de experiências que encontra no curso de sua vida.

Outras atividades, envolvendo o responsável de biblioteca e o profissional contador de histórias para o estimulo a leitura, também acontecem e são muito significativas, pois a arte de contar história tem uma existência longa, desde que os homens aprenderam a se comunicar. Um experiente contador de história sabe provocar poderosas emoções em seu público. Para Sandroni e Machado (1986) isso está representado pela Hora do conto. O objetivo dessa prática é a familiarização com a literatura, mostrada como entretenimento. Através dela, até os alunos menos amigos dos livros sentem-se encantados porque, para eles, ouvir é muito mais fácil do que ler; e o narrador, com as modulações da voz e as expressões faciais, contribui para tornar mais compreensíveis os significados e mais vivas as situações e as personagens.

A hora do conto provoca a curiosidade das crianças, principalmente quando vem acompanhada com personagens da história infantil. A narração do conto pode acontecer de diferentes formas e em diversas circunstâncias, como: leitura direta no livro; contação oral; uso de imagens do livro; oralidade e adereços (cenário, fantoches, personagens, etc.), dentre outras opções. Há também atividades seguidas de oficina de bonecos que complementam a narração. Com isso, as crianças são induzidas a descobrir na biblioteca o livro utilizado para a narração da história. Para Sandroni e Machado (1986, p. 36) 
[...] os resultados têm sido significativos, uma vez que as crianças, estimuladas pela história, se interessam a ler outros livros, conhecer outros autores novos e, até mesmo, descobrir novos caminhos, afastando-se da leitura rotineira e quiçá inadequada.

Percebe-se que o discurso do responsável que atende na biblioteca, em alguns momentos, pareceu contraditório com o do professor. Contudo, os responsáveis parecem ter prazer em informar que a biblioteca trabalha em parceria com o professor na troca de informações e acompanha o processo de ensino-aprendizagem realizado na instituição de ensino em que atua. Seu âmbito de ação vai desde a disponibilização de matérias para as atividades propostas, a busca de ajuda de pessoas de fora, a realização de palestras e o apoio ao desenvolvimento de trabalhos, a participação em olimpíadas, onde o aluno pode usar o espaço da biblioteca para práticas que estão fora de sua rotina. Para Macedo (2005, p. 335), considerando esse tipo de realidade,

[...] o intercâmbio de informações e conhecimentos entre o pessoal da biblioteca e da escola é vital para a operacionalidade do uso da biblioteca escolar e a conseqüente sedimentação do processo ensino-aprendizagem e acesso a informação.

Outra forma de interação se dá entre os alunos e a escola, principalmente após as visitas a feira; eles retornam mais motivados para o empréstimo de livros e para as atividades desenvolvidas na biblioteca, assim como para a troca e doação de materiais. Em vários momentos participam de atividades fora da rotina escolar como visitas ao caminhão do Ziraldo, participação nos concursos da Câmara Catarinense de Livros, premiação nesses concursos e viram que alguns textos por eles produzidos na escola foram publicados no livro da Câmara Catarinense do Livro.

\section{CONCLUSÕES}

$\mathrm{Na}$ pesquisa se procurou conhecer a opinião dos professores e dos responsáveis pela biblioteca sobre a contribuição que a visita dos alunos à Feira de Rua de Livros de Florianópolis produz no incentivo à leitura após visita à mesma.

Os resultados obtidos, de uma maneira geral, possibilitaram esse conhecimento e pode-se perceber que a feira oferece uma estrutura cujo foco é buscar a melhor alternativa de atendimento ao seu público; e que as crianças e jovens são os que mais estão em destaque nas suas edições. 
Constatou-se que os professores das escolas estudadas estão preocupados com a questão da leitura. Há a busca no sentido de incremento de várias ações para o desenvolvimento dessa prática muitas vezes com escassos recursos e muita criatividade.

Percebeu-se que os profissionais que atuam na biblioteca, dentro das condições que a biblioteca oferece, tentam desenvolver e proporcionar aos alunos e professores materiais para as atividades propostas no Projeto Político Pedagógico e também participam na elaboração do mesmo. Embora faltem melhores meios para que a biblioteca escolar possa ser mais atuante, observa-se interesse dos profissionais para que comecem a acontecer eventos que divulguem um pouco mais estas instituições e, de certa forma, com um pouco de lentidão isto vem acontecendo.

Por fim, levando-se em conta a questão principal que orientou a pesquisa, pode-se dizer que a visita à Feira de Rua Livros tem contribuído para o crescimento do interesse pela leitura em sala de aula e na biblioteca.

\section{REFERÊNCIAS}

ALVES, Magda. Como escrever teses e monografias: um roteiro passo a passo. Rio de Janeiro: Campus, 2003.

BERGER, Peter L.; LUCKMANN, Thomas. A construção social da realidade: tratado de sociologia do conhecimento. 9 ed. Petrópolis, RJ: Vozes, 1985. CÂMARA BRASILEIRA DE LIVROS. São Paulo. Disponível em:<http://www.cbl.org.br/content.php?recid=28>. Acesso em: 21 out. 2008.

EARP, Fábio Sá; KORNIS, George. A economia da cadeia produtiva do livro. Rio de Janeiro: Banco Nacional de Desenvolvimento Nacional, 2005. Disponível em:

<http://www.bndes.gov.br/conhecimento/ebook/ebook.pdf>. Acesso em: 21 out. 2008.

FREIRE, Paulo. Política e educação. São Paulo: Cortez, 1993.

GIL, Antonio Carlos. Como elaborar projetos de pesquisa. 3 ed. São Paulo: Atlas, 1993.

HIPERLIBRO. El comercio del libro. Argentina, [200-?]. Disponível em:

<http://www.hiperlibro.net/contenidos/El\%20comercio\%20del\%20libro.pdf>. Acesso em: 21 abr. 2009.

IBGE. Pesquisas de informações básicas municipais: gestão pública 2005. Disponível em:<http://www.ibge.gov.br/home/presidencia/noticias/noticia_visualiza.php?id_noticia=744\&id_pa gina=>. Acesso em: 21 out. 2008.

LEFÈVRE, Fernando; LEFÈVRE, Ana Maria Calvanti. O discurso do sujeito coletivo: um novo enfoque em pesquisa qualitativa (desdobramentos). 2 ed. Caxias do Sul: EDUCS, 2005. 
MACEDO, Neusa Dias de. Biblioteca escolar brasileira em debate: da memória profissional a um fórum virtual. São Paulo: SENAC: Conselho Regional - 8ª Região, 2005.

MANGUEL, Alberto. A biblioteca à noite. São Paulo: Companhia das Letras, 2006.

MINAYO, Maria Cecilia de Souza (org). Pesquisa social: teoria, método e criatividade. 21. ed. Petrópolis: Vozes, 2002.

OLIVEIRA, Lívio Lima de. Breve histórico das práticas de aquisição de livros no Brasil. In: CONGRESSO BRASILEIRO DE CIÊNCIAS DA COMUNICAÇÃO, 31., 2008. Natal. Anais... Natal: USP, 2008. 1-11. Disponível em:<http://www.intercom.org.br/papers/nacionais/2008/resumos/R31588-1.pdf>. Acesso em: 21 abr. 2009.

SANDRONI, Laura Constancia; MACHADO, Luiz Raul (orgs.). A criança e o livro: guia prático de estímulo à leitura. São Paulo: Ática, 1986.

SINDICATO NACIONAL DE EDITORES DE LIVROS. São Paulo. Disponível em: <http://www.snel.org.br/ui/institucional/estatuto.aspx>. Acesso em: 21 out. 2008.

ZEN, Maria Isabel H. Dalla. Histórias de leitura na vida e na escola: uma abordagem lingüística, pedagógica e social. Porto Alegre: Mediação, 1997. .

\title{
Title
}

Florianópolis' Book Street Fair as a stimulating environment for reading activities in schools

\begin{abstract}
It presents a paper which aimed to analyze the teachers and school libraries staff discourses about the reading stimulation effect on pupils from two schools, who had the opportunity to take part in 2007 and 2008 at the Book Street Fair in Florianópolis. The data collecting procedure was applied using a verbal technique composed by eight open questions. The study was conducted with four teachers, two Geography teachers, one Portuguese teacher, and another primary school teacher, as well as with two professionals responsible for the libraries from the two schools involved in the research. The exploratory research employed the Collective Subject Discourse technique for the analysis of the verbal data collected. Based on the results, it was possible to conclude that the fair reading activities contributed to a greater involvement of students in reading activities at school.
\end{abstract}

\section{Keywords}

Fair Street book. Reading. School library.

\section{Título}

La "Feria de la Calle de Libros de Florianópolis" como ambiente estimulador de la lectura en la escuela 


\section{Resumen}

Presenta resultado de investigación cuyo objetivo fue analizar los discursos de los profesores y del personal actuante en las bibliotecas de las escuelas de la red de enseñanza de Florianópolis acerca de la estimulacion que las actividades para fomentar la lectura ofrecidas a los alumnos de dos escuelas en la Feria de Calle de Libros de Florianópolis, en los años de 2007 y 2008, ejercieran sobre ellos. En la colecta de datos se aplico entrevista verbal con ocho preguntas abiertas. Los participantes del estudio fueron cuatro profesores, dos de Geografía, uno de Portugues (los tres del 5․ al $8^{\circ}$. grados), una maestra del $2^{\circ}$. grado y dos profesionales que prestan servicios como responsables por el atendimiento en las bibliotecas de las escuelas. La investigación, de carácter exploratório, empleó la técnica del Discurso del Sujeto Colectivo (DSC) para el tratamiento y análisis de los datos recogidos. De los resultados obtenidos, se puede decir que las actividades de lectura disponibles en la Feria de Calle de Livros han contribuido a una mayor participación de los estudiantes en las actividades de lectura en la escuela.

\section{Palabras Clave}

Feria de la Calle del Libro. Fomento a la lectura. Biblioteca de escuela.

Recebido em: 18.09.2009

Aceito em: 09.03.2010 